\title{
analysis
}

\section{Overcoming resistance}

\author{
Rather than waiting for new drugs, surveillanceand education might bemore efficient strategies to combat \\ rising antimicrobial resistance
}

$\mathrm{R}$ esistant bacteria rarely make the headlines these days. However, in March 2004, The N ew York Times reported a new strain of community-acquired methicillinresistant Staphylococcus aureus (caMRSA), which is much more aggressive than its hospital brethren and has a particular preference for the young and healthy (Zuger, 2004). Indeed, caMRSA is biologically different from methicillin-resistant hospital strains and no one knows where it came from or how it emerged. "This is a resistant bug that's been in the news because of the way it's affected competitive sports participants, including professional football here in the United States, correctional facilities, Native Americans, and paediatric populations," said Todd W eber of the US Centers for Disease Control and Prevention (CDC; Atlanta, GA, USA). "Although we don't have surveillance data to show it, it really appears that it's increasing." This latest case of antibiotic resistance again highlights the dangers of antibiotic misuse and the need for efficient strategies to fight bacterial diseases.

Antibiotics are a godsend against bacterial diseases, but they have their w eaknesses. Unfortunately, whether carefully used or carelessly abused, consumption of these drugs will eventually lead to the emergence of resistance. The most obvious way to tackle this problem is to develop new antibiotics, but, if anything, drug companies are investing less in antibiotic drug development than ever before. Faced with this situation, publichealth experts are returning to old strategies for fighting disease- surveillance and education - to make better use of the medicines available. In Europe, two ambitious international efforts monitor antibiotic use and resistance, but surveillance is more difficult in the USA owing to the absence of a national health service. N evertheless, several government agencies have begun to collaborate

\section{... if a causal link between antibiotic consumption and resistance can be shown, it will greatly help public-health experts to draft new guidelines...}

and implement widespread educational campaigns to counter the rise of antibiotic resistance in hospitals and the community.

Since the first antibiotic, penicillin, became available in the 1940 s, bacteria have shown cunning inventiveness in developing resistance. They easily swap resistance genes and any bacteria that survive exposure to an antibiotic will replicate and produce resistant offspring. Even without exposure to antibiotics, a small fraction of any population of bacteria might spontaneously acquire mutations that confer resistance. Generally, experts believe that the over-prescription of antibiotics is behind the increase in drugresistant bacteria. When doctors prescribe antibiotics for non-bacterial infections, or patients stockpile antibiotics or use them incorrectly, resistance is inevitable. This is further compounded by the use of antibiotics in animal husbandry and an increase in the number of antibacterial cleaning products, both of which leak into the environment where they can cause further resistance.

T he battle against bacterial diseases cannot be fought without the pharmaceutical industry, but drug companies have been focusing less and less on the development of new antimicrobials, for a range of reasons (Moore, 2003). It is difficult to find new drug targets and new antibiotics are often reworked versions of previously approved drugs, and are subject to the same mechanisms of resistance that emerged in response to the original treatment. Ultimately, other areas of drug development make more economic sense. "The pharmaceutical companies have left the field because the profit margin isn't as attractive as other areas of medicine," commented Stuart Levy, Director of the Center for Adaptation Genetics and Drug Resistance at Tufts University School of Medicine (Boston, M A, USA).

\section{Although the USA has yet to establish a national surveillance system, they have had great success battling tuberculosis...}

In addition, it is particularly difficult to get new antibiotics approved. In 2002 and 2003, the total number of US and European drug approvals was lower than any figure since the early 1990s: the US Food and Drug Administration (FDA) approved two antibiotics, and the centralized European Medicines Evaluation Agency (EMEA) approved only one. One reason for this is the demanding and complicated regulatory process. It is often impossible to find sufficient candidates for a clinical trial if the drug in question is designed to work against multi-drug-resistant bacteria. Drug testing also faces ethical challenges: should someone suffering from such an infection be subject to an unapproved trial drug if a licensed drug is available? Although both the FDA and EM EA are looking into ways to facilitate drug approval for antibiotics in particular, this will not address the main concern of the pharmaceutical companies-antibiotics are not big money-makers, especially if their use is limited by resistance. "The unresolved problem is that you want drug companies to produce more drugs but you don't want them used too much. Simply stated, that's the economic dilemma. We have not overcome that problem yet," Weber said. 
l nstead of waiting for new 'silver bullets', surveillance and education may be more efficient strategies. Recognizing this fact, two European groups have started complementary programmes to collect antibiotic resistance and consumption data across the continent. The European Surveillance of Antimicrobial Consumption (ESAC) network (www.ua.ac.be/esac), headed by project leader Herman Goossens at the University of Antwerp in Belgium, tracks hospital and outpatient antibiotic usage. Linking these data to the resistance data collected by the European Antimicrobial Resistance Surveillance System (EARSS; www.earss.rivm.nl) will allow scientists to analyse the trends in greater detail. "The pilot project was basically establishing the network and the method. In the second phase, we will try to go beyond this and try to understand what's behind [the data]," Goossens said. Although the project is still in progress, it has already created much interest. "The data that come from these two organizations are very impressive," said Philip Jenkins from the Antimicrobial Resistance Unit of the Department of Essential Drugs and M edicines Policy at the W orld Health Organization (WHO; Geneva, Switzerland).

EARSS collects data from more than 700 laboratories and 1,100 hospitals in 28 countries, which cover 100 million inhabitants of the European Union (EU), while ESAC covers 31 countries. Results from both surveillance systems show similar trends across Europe: "Broadly speaking, we see a north-south gradient with resistance high in the Mediterranean countries and lower in northern Europe," explained Hajo Grundmann, EARSS project leader. Consumption also tends to be higher in southern European countries and lower in the north. Whether this indicates a link is still subject to further analysis. "A simple one-to-one relationship of consumption to resistance is a naive concept," Grundmann cautioned. "Antimicrobial consumption is certainly one, but I emphasize only one, of the aspects that explains these differences."
The ESAC data agree closely with a previous, more limited assessment of antibiotic consumption in Europe (Cars et al, 2001). The use of antibiotics in ambulatory (that is, non-hospital) care is higher in southern European countries, such as France, G reece, Italy, Portugal and Spain, and lower in northern European countries, such as the Netherlands, Denmark and Sweden. In 2001, France used over three times as many defined daily doses per 1,000 inhabitants

Nevertheless, if a causal link between antibiotic consumption and resistance can be shown, it will greatly help public-health experts to draft new guidelines, although some experts remain cautious about such simplifications. "A lot of factors, demographics, social, economic and healthcareassociated factors need to be taken into account," Grundmann said. But Jenkins pointed to evidence from Switzerland showing a link between consumption and resistance, and the ease with which resistance spreads. The distribution of antimicrobial resistance across Switzerland shows a distinct east-west trend, with higher levels of resistance in western parts around Geneva than in eastern parts. To the west of Switzerland is France, which has high levels of antibiotic consumption. Moving towards Germany and Austria, which have more stringent controls and lower use of antibiotics, resistance becomes lower.

W hile the European surveillance system has begun to yield results, "the Americans have not been so successful," Goossens said. Indeed, the lack of a national health service in the USA makes tracking resistance and consumption data more difficult. Several local surveillance systems have been established in collaboration with state health departments and hospitals, but as far as comprehensive surveillance is concerned, "I think that's something we'd very much like to improve here in the U nited States," Weber said. An Interagency Task Force on Antimicrobial Resistance, implepublic against antibiotic misuse. Reproduced with permission from theUK Department of Health.

per day (DID) as the Netherlands. O ften, neighbouring countries have similar levels of consumption, as is the case for G ermany and Austria, or Norway and Sweden. However, this is not always the case; in 2001, Belgium had a DID level more than twice that of its Dutch neighbours. This might be owing to differences between the healthcare systems of the two countries (Coenen et al, 2001), which might also account for other differences across Europe. mented in 1999, linked the CDC, FDA and National Institutes of Health $(\mathrm{NIH})$ with a range of other governmental organizations mostly from within the US Department of $H$ ealth and Human Services. "This is really a multifactorial problem and one agency's skills and oversight really aren't enough to tackle the problem," W eber said.

Although the USA has yet to establish a national surveillance system, they have had great success battling tuberculosis (TB), an 


\section{The freedom of movement throughout theEU that citizens of theten accession countries now enjoy might also have effects on thespread of infectious diseases and antimicrobial resistance}

infection that is notoriously resistant to treatment. The CDC tracks every case in the country, noting not only the sensitivities of the microbe but also the drugs that the patient is taking and whether they finish their prescription. In the early 1990s, the New York City Department of Health in the USA implemented the directly observed therapy (DOT) system to deal with the alarming increase in TB cases in the city. The DOT system ensures that patients complete their course of antibiotic treatment by, as the name suggests, directly observing them. Since then, cases have steadily decreased and resistance is now rare in the USA. "This is a much larger problem in other parts of the world, notably Russia and in their prison system in particular, but even so I think surveillance [... ] has really led the way in being able to control the TB problem in the U nited States," W eber said.

However, the disease might still come back to haunt Europe. Now that the three former Soviet republics Latvia, Estonia and Lithuania have joined the EU, TB might soon follow. Although Latvia has successfully implemented a DOT strategy to curb multidrug-resistant TB, the prevalence of communicable diseases and health-care-system frailties in Eastern European countries are troubling (Coker et al, 2004; Durrheim \& Speare, 2004). The freedom of movement throughout the EU that citizens of the ten accession countries now enjoy might also have effects on the spread of infectious diseases and antimicrobial resistance. "This is difficult to predict," Grundmann said. "Free movementmay of course be of some concern for the characteristic communicable diseases such as TB and certainly multi-drug resistant TB. For nosocomially (in-hospital) transmitted or communicable pathogens such as Streptococcus pneumoniae, Central and Eastern European countries enjoy some sort of slower development of antimicrobial resistance than Western European countries, but that may well change."

Indeed it may, given the trends of antibiotic consumption. "[In] Eastern Europe, there are fairly high sales of over-the-counter antibiotics," Jenkins said. Goossens agreed, "O ur impression is that marketing is much more aggressive nowadays in Central and Eastern European countries, and much less so in Western European countries." Although consumption in general is decreasing in the first 15 member states of the EU, consumption in Eastern European countries continues to increase. ESAC has shown that some drugs are being used to treat infections for which they are not normally recommended. "We have the impression that there's a lot of pressure from the pharmaceutical industry on these Central and Eastern European countries to increase consumption, therefore increasing the benefits [for the pharmaceutical industry]," Goossens said.

$O^{r}$ urveillance to recognize rising antibiotic resistance and identify its causes is only the first step, and must be followed by educating the public and policy makers. In the USA, the CDC has launched 'G et Smart: Know When Antibiotics Work', a publichealth campaign directed at the public and physicians by using print, radio and television advertising. At an international level, the WHO released their Global Strategy for Containment of Antimicrobial Resistance in September 2001, with more than 60 recommended interventions, including education for patients and the general community, prescribers and dispensers, and national governments and health systems. The nonprofit international Alliance for Prudent Use of Antibiotics (Boston, MA, USA; www.apua.org) also conducts educational activities to promote the appropriate use of antibiotics worldwide.

In Europe, ESAC has already gathered ample arguments for change. As Goossens said, "If you look at France and you look at the N etherlands, people are not dying in the street of infections in the Netherlands, although they use 3-4 times less antibiotics." When policy makers start questioning these differences in consumption, they will probably be more inclined to educate the public on the prudent use of antibiotics. In addition, any successful campaign has to start at the bottom with the patients and their physicians. "We have to convey the message that modern lifestyle does not include deliberate antibiotic use for minor infection and this message has to be directed at ambulatories and family doctors before industry arrives with glossy prints and become opinion leaders," Grundmann said. Levy agreed: "An effective campaign against resistance has to be at the local level with amplification at the national and international level."

\section{Perhaps the biggest obstacle to tackling resistance is the fact that too many peopleaccept it as inevitable}

Some smaller European countries, such as the Netherlands and Finland, have already lowered antibiotic resistance by increasing public awareness and curbing consumption. Jenkins also noted that some Western European and Scandinavian countries implemented many of the W HO recommendations for combating antimicrobial resistance. According to Levy, success in reducing antibiotic resistance relates to the size of a country and the strength of its government, although this requires further analysis. "It would take some time to decipher or articulate exactly what are the differences that make one country able to implement change but not another," he said.

Perhaps the biggest obstacle to tackling resistance is the fact that too many people accept it as inevitable. As Weber explained, "even if drugs were used exquisitely perfectly, the emergence of drug resistance is likely." Also, this problem does not receive much attention compared with other health issues-recent scares, such as severe acute respiratory syndrome (SARS), avian flu and bioterrorism, have clearly overshadowed the distant possibility of bacterial resistance with the short-term fear of imminent danger. However, Levy, who highlighted the dangers of antibiotic resistance more than a decade ago in his book The Antibiotic Paradox, feels that public awareness is slowly increasing. "The message is out there," he said. The next step is overcoming resistance to change.

\section{REFERENCES}

Cars O, M ölsad S, M elander A (2001)Variation in antibiotic use in the European U nion. Lancet 357: 1851-1853

Coenen S, Kuyenhoven M M , Butter CC, Van Royen P, Verheij TJM (2001)Variation in European antibiotic use. Lancet 358: 1272

Coker RJ, Atun RA, M cKee M (2004) Health-care system frailties and public health control of communicable disease on the European U nion's new eastern border. Lancet 363: 1389-1392

Durrheim D N, Speare R (2004) Communicable disease surveillance and management in a globalised world. Lancet 363: 1339-1340

Moore A (2003) The big and small of drug discovery. EMBO Rep 4: 114-117

Zuger A (2004) Bacteria run wild, defying antibiotics. N ew York Times, 2 March, F1

\section{CarolineHadley}

doi:10.1038/sj.embor.7400181 